\title{
Characteristics of Paraffin Shielding of Kartini Reactor, Yogyakarta
}

\author{
Lana Khanifah ${ }^{1,{ }^{*}}$, Susilo Widodo ${ }^{2}$, Widarto ${ }^{2}$, Ngurah Made Dharma Putra ${ }^{1}$, and Argo Satrio ${ }^{2}$ \\ ${ }^{1}$ Department of Physics, Faculty of Mathematics and Natural Sciences, Universitas Negeri Semarang, Semarang 50229, Indonesia \\ ${ }^{2}$ Center of Accelerator Science and Technology, National Nuclear Energy Agency, Yogyakarta 55281, Indonesia \\ *Corresponding authors: lana.khanifah@gmail.com
}

\section{KEYWORDS}

BNCT

Paraffin

Radiation shielding
ABSTRACT The National Nuclear Energy Agency (BATAN) Yogyakarta uses two kinds of paraffin for shielding radiation of Kartini reactor. For developing BNCT research, the radiation attenuation capability of paraffin has been analyzed to find out the coefficient attenuation, density, and composition of both kinds of paraffin. The components of the paraffin were analyzed using Fourier transform infrared (FTIR) spectroscopy, scanning electron microscopy (SEM), and energy dispersive X-ray (EDX) spectroscopy characterization. Paraffin $\mathrm{P} 1$ has a density of $0.689 \mathrm{gr} / \mathrm{mL}$ and paraffin $\mathrm{P} 2$ is $0.578 \mathrm{gr} / \mathrm{mL}$. Paraffin samples $\mathrm{P} 1$ and $\mathrm{P} 2$ were the sample content of functional group $\mathrm{CH}, \mathrm{CH}_{2}$, and $\mathrm{OH}$ when analyzed by FTIR. Paraffin P2 had an additional content namely $\mathrm{CO}$. The concentration of carbon (C) and oxide (O) of paraffin P2 was much greater than that of paraffin P1. Hydrogen $(\mathrm{H})$ in the paraffin has the function of moderating neutrons, but hydrogen content in both kinds of paraffin could not be detected by EDX. The acquired neutron coefficient attenuation of paraffin $P 2$ was $0.0382 \mathrm{~cm}^{-1}$ and the gamma coefficient attenuation was $0.0535 \mathrm{~cm}^{-1}$.

(c) The Author(s) 2018. This article is distributed under a Creative Commons Attribution-ShareAlike 4.0 International license.

\section{INTRODUCTION}

Nuclear energy has been used in many sectors, such as industry, agriculture, medicine, and in warfare. Nuclear energy has a negative impact caused by nuclear radiation, in the form of gamma and neutron. The Center of Accelerator Science and Technology at the National Nuclear Energy Agency of Indonesia (BATAN) has been developing Boron Neutron Cancer Capture Therapy (BNCT), a method for treating cancer that uses neutron radiation.

Boron neutron cancer capture therapy (BNCT) is a tumor selective treatment modality (Kankaanranta et al. 2012). It is a method of radiation therapy based on the interaction of neutron with non-radioactive nuclide Boron-10 $\left({ }^{10} \mathrm{~B}\right) .{ }^{10} \mathrm{~B}$ absorbs the neutron and releases two linear energy transfer particles, an alpha $\left({ }^{4} \mathrm{He}\right)$ and lithium $\left({ }^{7} \mathrm{Li}\right)$ nucleus (Yura and Fujita 2013). In order to safely deploy the BNCT system, radiation shielding is required to provide protection from nuclear radiation. The shielding materials are used to mitigate the harmful effects of neutron particles. These shielding materials may include water, paraffin wax, boron, and several metals that have a high atomic number (such as tungsten or tantalum) (Aygün et al. 2015).

BATAN's Center of Accelerator Science and Technology in Yogyakarta has two kinds of paraffin that can be used for radiation shielding. Analysis of this paraffin is needed for evaluation of the attenuation capability of paraffin shielding. Understanding the coefficient attenuation, density, and composition of paraffin will aid in the development of BNCT. Paraffin is a form of an alkena compound that is composed of a hydrocarbon bond. Paraffin has a high cross section and capability for arresting and moderating the rapid movement of the neutrons. Neutrons that radiate collide with the hydrogen on paraffin, thus moderating the rapid movement of these neutrons (Buyuk and Tugrul 2014; Piotrowski et al. 2015).

Neutrons are uncharged particles and do not have a direct Coulomb interaction with nuclei and electrons. The magnetic interaction between neutrons and electrons is one million times smaller than the magnetic interaction in charged particles. The neutrons that come up into the atom field have the opportunity to interact with the nucleus, either in scattering or absorption (Ding et al. 2015).

The collision of neutrons and the nucleus causes some of the neutron's energy to be transferred to the nucleus of the atom, causing the rapid movement of the neutrons to decrease or be moderated. This collision results in the neutrons scattering and radiating gamma $(\gamma)$. An elastic collision of neutrons and nucleus occurs when all of the neutron's energy is lost. This can occur in one collision if the masses of the neutrons and the nucleus are equivalent.

Meanwhile, the absorption of neutrons by the nucleus occurs when the kinetic energy of the neutrons is absorbed by the nucleus. The nucleus becomes excited and is in an unstable condition, and is induced to create a new nucleus that radiates $\alpha, \beta$, and $p$ particles (Piotrowski et al. 2015).

When these neutrons meet heavy metal materials, inelastic scattering occurs first and after one or two inelastic collisions, and the neutrons lose most of their energy. The scattering consequently turns into the elastic scattering phase. At this phase, the materials with a high content of protons are most effective for neutron moderating. Hydrogen-rich materials with high density, such as polyethylene, paraffin wax and water are selected. 


\section{MATERIALS AND METHODS}

The capability of paraffin to act as a neutron shielding was analyzed by determining the density of paraffin and the compound composition, as well as by calculating the coefficient attenuate of the paraffin. There were two kinds of paraffin used, titled sample P1 and sample P2. P1 was paraffin that has already been used as shielding in the National Nuclear Energy Agency of Indonesia's (BATAN) Kartini Reactor. P2 was another paraffin that had several of block shapes, and had not yet been use as radiation shielding in Kartini Reactor.

\subsection{Determination of the density of paraffin}

The density of paraffin P1 and P2 was determined by calculating the mass and volume of the samples. Sample P1 and P2 were cut into small blocks and the mass was measured by pair of digital scales. The volume of paraffin was determined by placing the small block of paraffin into a measuring glass containing water. The volume of paraffin was shown by the increase of water volume in the measuring glass. The density of the paraffin was determined using Equation 1.

$$
p=\frac{m}{v}
$$

where $p$ is the density of paraffin $\left(\mathrm{kg} / \mathrm{m}^{3}\right), m$ is the mass of paraffin $(\mathrm{kg})$, and $v$ is the volume of paraffin $\left(\mathrm{m}^{3}\right)$.

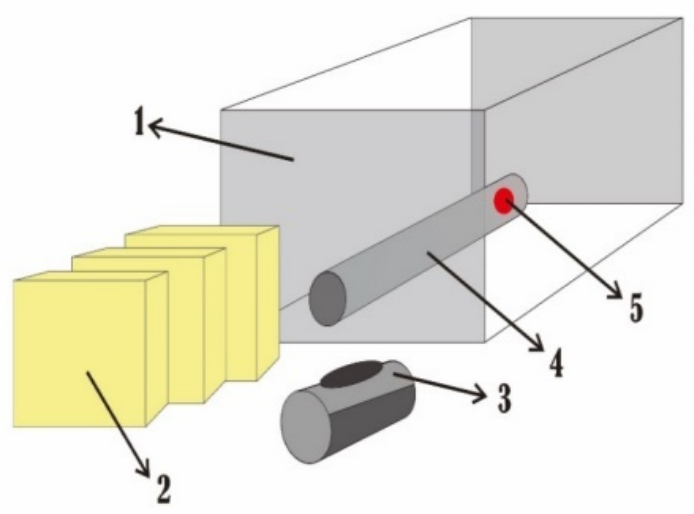

FIGURE 1. Materials of neutron irradiation: container $\mathrm{Pb}$ (1); paraffin block (2); neutron and gamma detector (3); pipe as a collimator (4); isotopic neutron source Pu-Be (5).

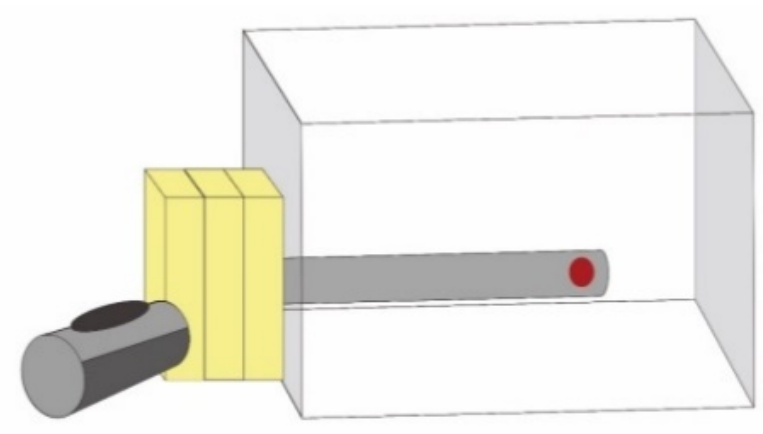

FIGURE 2. Irradiation process.

\subsection{Characterizing paraffin structure and compound com-} position

The structure of paraffin was determined using Fourier Transform Infrared spectroscopy (FTIR) and Scanning Electron Microscopy-Energy Dispersive X-ray spectroscopy (SEM/EDX). Samples P1 and P2 were refined into powder using a mortar and pestle, and then characterized with FTIR and SEM-EDX. Fourier Transform Infrared spectroscopy-based (FTIR) characterization of the paraffin was undertaken to determine its chemical bond. The resolution of FTIR was set at $4 \mathrm{~cm}^{-1}$ and the spectral region was $450-4000 \mathrm{~cm}^{-1}$ with data interval of 1 . Scanning Electron Microscopy (SEM) was used to reveal the appearance of the paraffin structure, while EDX-based characterization was used to determine the compound composition of the paraffin samples.

\subsection{Irradiation of paraffin used by the neutron source}

The third form of analysis encompassed measuring the attenuation coefficient of paraffin sample P2. The materials used for this experiment were an isotopic neutron source $(\mathrm{Pu}-\mathrm{Be}), \mathrm{a} \mathrm{Pb}$ container, a neutron and gamma detector, and a stopwatch. Irradiation was conducted in the $\mathrm{Pb}$ container containing the isotopic neutron source $(\mathrm{Pu}-\mathrm{Be})$, as shown in Figure 1.

Flux radiation of the $\mathrm{Pu}-\mathrm{Be}$ source was shown in the gamma and neutron detector, which was placed at the mouth of a tube (Figure 2). Flux radiation of the neutron and gamma that was detected without paraffin shielding at the mouth of the tube were named initial flux radiation $\left(\mathrm{I}_{0}\right)$. Then paraffin blocks were placed one by one in front of the tube to be used as radiation shielding, and the flux radiation was measured in the detector. The radiation that showed was named flux radiation $\mathrm{i}-\mathrm{st}\left(\mathrm{I}_{\mathrm{i}}\right)$. Irradiation was performed at various thicknesses of paraffin, namely 4.5 $\mathrm{cm} ; 8.3 \mathrm{~cm} ; 14.1 \mathrm{~cm}$; and $22.6 \mathrm{~cm}$.

\section{RESULTS AND DISCUSSION}

\subsection{Density of paraffin}

The result of measuring the mass and volume of paraffin samples P1 and P2 is shown in Table 1. Using Equation 1, the density of samples P1 and P2 could be calculated, and was found to be $0.689 \mathrm{gr} / \mathrm{mL}$ and $0.578 \mathrm{gr} / \mathrm{mL}$, respectively.

\subsection{Structure and compound composition}

\subsubsection{FTIR analysis}

The compound structure of the paraffin, revealed using FTIR, is shown in Figures 3 and 4. The compound composition of the paraffin samples can be found from the FTIR characterization result. The result of this infrared spectroscopy is shown in the graphic as a wave number (1/wavelength) and a transmittance percent. Peaks in this graphic are the identification of the chemical compound that makes up this paraffin. The peak identification of each sample is shown in Table 2 and 3.

TABLE 1. Mass and volume P1 and P2.

\begin{tabular}{llll}
\hline No & Sample name & Mass $(\mathrm{gr})$ & Volume $(\mathrm{mL})$ \\
\hline 1 & P1 & $5.202 \pm 0.005$ & $9.0 \pm 2.5$ \\
2 & P2 & $10.092 \pm 0.005$ & $14.5 \pm 2.5$ \\
\hline
\end{tabular}


In Figure 5, a comparison of the FTIR peaks of both sample P1 and sample P2 is shown. Both samples have an identical peak in terms of height at regions 2957-2800 and 1470-1380. This indicates that the compound composition of both paraffins was identical. The difference in transmittance height between the two samples was neglected, because the quantity of $\mathrm{KBr}$ used to make the $\mathrm{P} 1$ and $\mathrm{P} 2$ pellets was not noted.

The ratio between the heights of the peaks at $2957 \mathrm{~cm}^{-1}$ indicates that the samples were an alkane compound with a single hydrocarbon binding $(\mathrm{C}-\mathrm{H})$. The higher peak of both samples showed that both $\mathrm{P} 1$ and $\mathrm{P} 2$ contained $\mathrm{CH}, \mathrm{CH}_{2}$, and $\mathrm{OH}$ bindings. The appearance of another peak in paraffin sample P2 suggests that this paraffin contained a $\mathrm{CO}$ binding. Thus, it can be approximated that $\mathrm{P} 1 \mathrm{had}$ a $\mathrm{CH}$ binding that was much greater than that of $\mathrm{P} 2$.

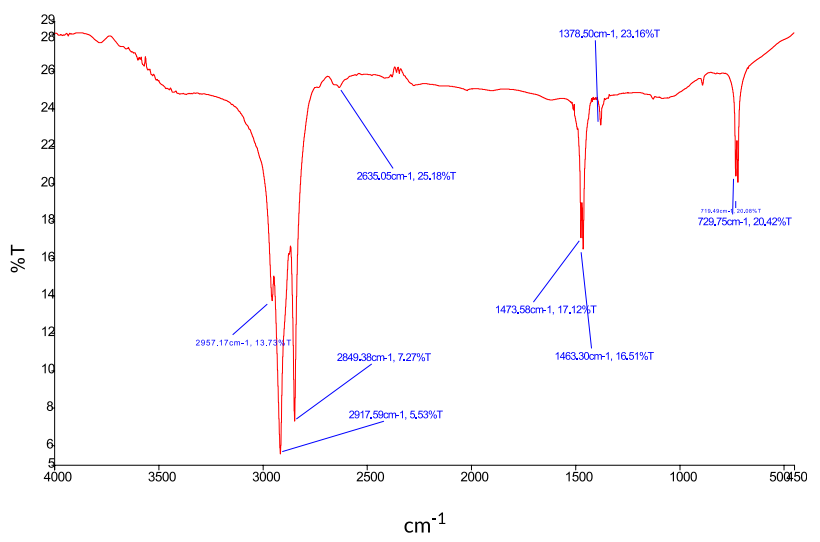

FIGURE 3. FTIR characteristics of paraffin sample P1.

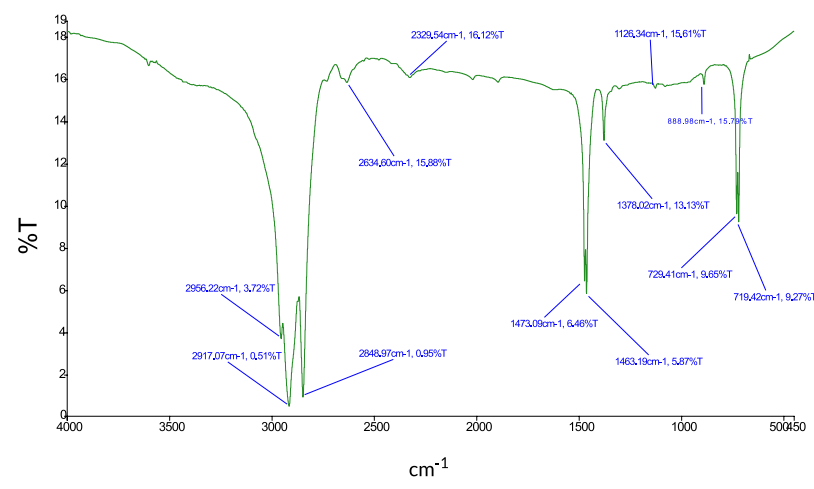

FIGURE 4. FTIR characteristics of paraffin sample P2.

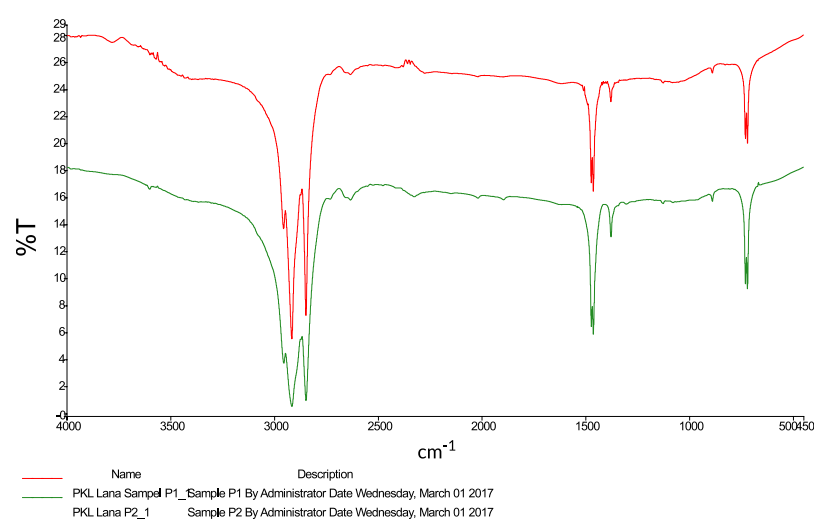

FIGURE 5. Comparison of FTIR peaks of paraffin samples $\mathrm{P} 1$ and $\mathrm{P} 2$.

\subsubsection{SEM-EDX analysis}

The SEM result, which revealed the appearance of the powder of paraffin samples P1 and P2, is shown in Figure 6. In addition, the composition of the paraffin was analyzed using EDX. By choosing a random point of a sample, the element composition in that point can be found.

Based on the result of EDX, both of the paraffin samples were found to have a similar element composition, although the concentration in each sample was different. In sample P1, carbon composition was $23.2 \%$ while oxygen was $0.4 \%$. In comparison, sample P2's carbon composition was $31.6 \%$ and oxygen composition was $0.6 \%$. This corresponds with the FTIR result, which showed that the carbon and oxygen contents of P2 was greater than that of P1. Nevertheless, the hydrogen elements could not be detected using EDX result as shown in the FTIR result analysis, whereas C$\mathrm{H}$ binding was the major composition in the sample. This is because hydrogen is an organic element with a small atomic mass.

\subsubsection{Attenuation coefficient of paraffin shield}

Irradiation using isotopic neutron source $\mathrm{Pu}-\mathrm{Be}$ was performed by varying the thickness of paraffin sample P2 as radiation shielding. The result of this irradiation is shown in Table 4.

The results of irradiation can be analyzed to acquire the attenuation coefficient of sample P2. Using an irradiation equation and linear regression method, a neutron attenuation coefficient of $0.0382 \mathrm{~cm}^{-1}$ and the gamma attenuation coefficient of $0.0535 \mathrm{~cm}^{-1}$ was acquired. A graphic

TABLE 2. Peak FTIR result of sample P1.

\begin{tabular}{lll}
\hline No & Wavenumber $\left(\mathrm{cm}^{-1}\right)$ & Mode \\
\hline 1 & $2957.17-2849.38$ & $(\mathrm{C}-\mathrm{H})$ alkane \\
2 & 2635.05 & $(\mathrm{O}-\mathrm{H})$ \\
3 & $1473.58-1378.5$ & $(-\mathrm{C}-\mathrm{H})$ \\
4 & $729.75-719.49$ & $\left(\mathrm{CH}_{2}\right)$ \\
\hline
\end{tabular}

TABLE 3. Peak FTIR result of sample P2.

\begin{tabular}{lll}
\hline No & Wavenumber $\left(\mathrm{cm}^{-1}\right)$ & Mode \\
\hline 1 & $2957.17-2849.38$ & $(\mathrm{C}-\mathrm{H})$ alkane \\
2 & 2634.60 & $(\mathrm{O}-\mathrm{H})$ \\
3 & 2329.54 & $(\mathrm{C}-\mathrm{O})$ \\
4 & $1473.09-1378.02$ & $(-\mathrm{C}-\mathrm{H})$ \\
5 & 1126.34 & $(\mathrm{C}-\mathrm{O})$ \\
6 & 888.98 & $(\mathrm{C}-\mathrm{O})$ \\
7 & $729.41-719.42$ & $\left(\mathrm{CH}_{2}\right)$ \\
\hline
\end{tabular}

TABLE 4. Result of neutron and gamma radiation by paraffin shield.

\begin{tabular}{llll}
\hline No. & $\begin{array}{l}\text { Thickness } \\
\text { Xi }(\mathrm{cm})\end{array}$ & $\begin{array}{l}\text { Average radiation } \\
\text { intensity of neutron } \\
\text { (cps) }\end{array}$ & $\begin{array}{l}\text { Average radiation } \\
\text { intensity of gamma } \\
\text { (cps) }\end{array}$ \\
\hline 1 & 0 & 22.4 & \\
2 & 4.5 & 545.75 & 17.69 \\
3 & 8.3 & 501.5 & 14.48 \\
4 & 14.1 & 374.65 & 9.63 \\
5 & 22.6 & 280.25 & 6.83 \\
\hline
\end{tabular}




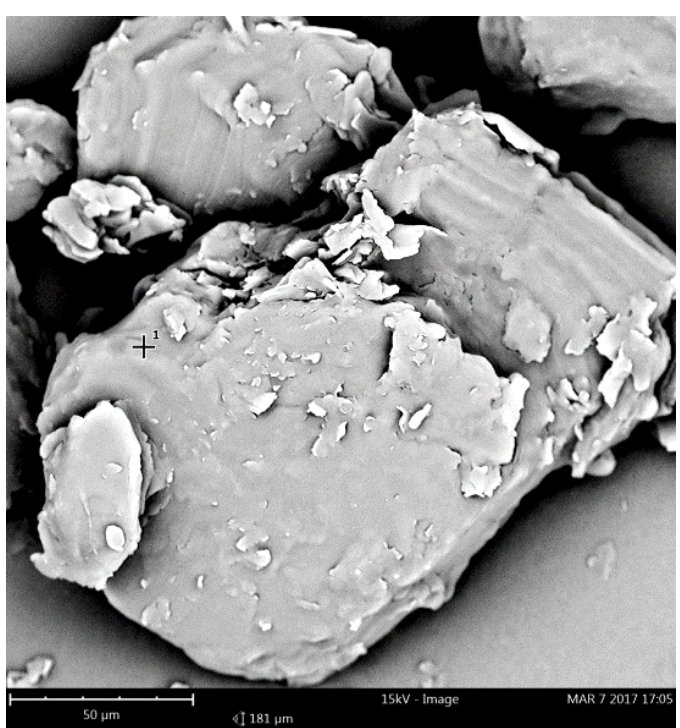

(a)

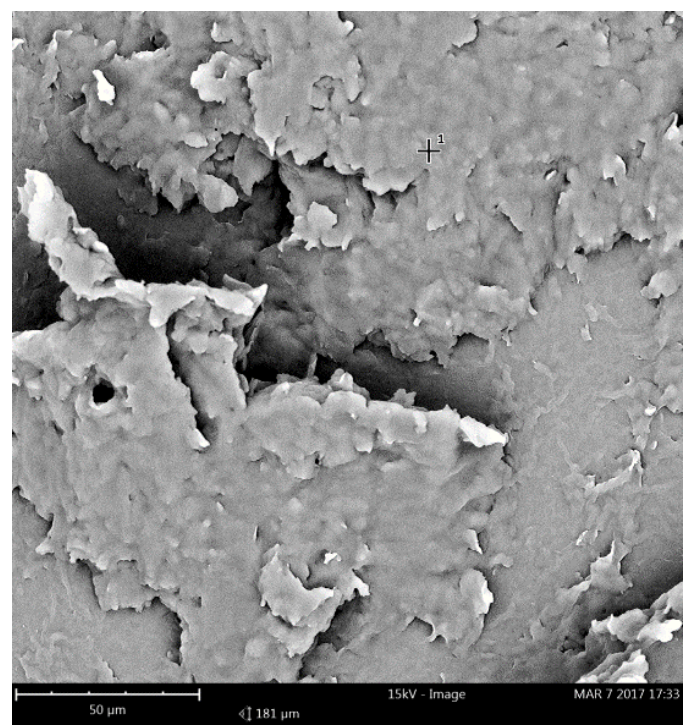

(b)

FIGURE 6. Structure of (a) sample P1, and (b) sample P2.

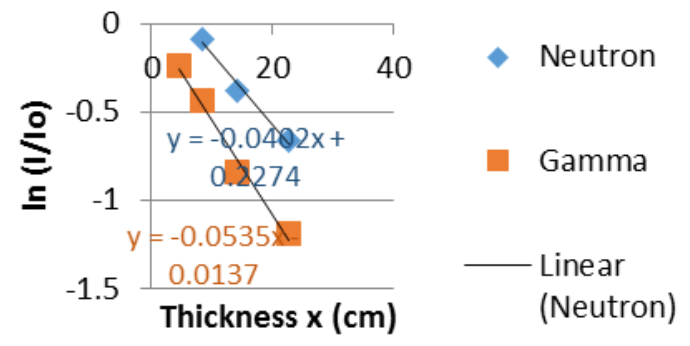

FIGURE 7. Shielding paraffin thickness and In (I/10) graphic

representing the paraffin shielding thickness and $\ln \left(\mathrm{I} / \mathrm{I}_{0}\right)$ is shown in Figure 7.

\section{CONCLUSIONS}

The characteristics of the paraffin shielding of BATAN's Center of Accelerator Science and Technology were determined. The density of paraffin samples P1 and P2 was 0.578 $\mathrm{gr} / \mathrm{mL}$ and $0.689 \mathrm{gr} / \mathrm{mL}$, respectively. Meanwhile, a content of $\mathrm{CH}, \mathrm{CH}_{2}$, and $\mathrm{OH}$ bindings was also found in both paraffin samples, while a $\mathrm{CO}$ binding was additionally discovered in sample P2. The neutron coefficient attenuation of paraffin sample P2 was $0.0382 \mathrm{~cm}^{-1}$ and gamma coefficient attenuation was $0.0535 \mathrm{~cm}^{-1}$.

\section{REFERENCES}

Aygün B, Korkut T, Karabulut A, Gencel O, Karabulut A. 2015. Production and neutron irradiation tests on a new epoxy/molybdenum composite. Int J Polym Anal Charact. 20(4):323-329. doi:10.1080/1023666X.2015.101779 0 .

Buyuk B, Tugrul AB. 2014. Gamma and neutron attenuation behaviours of boron carbide-silicon carbide composites. Ann Nucl Energy. 71:46-51. doi:10.1016/j.anucene. 2014.03.026.

Ding W, Nan HJ, Wu TF, Guo T, Wang BR, Shen RQ. 2015. Detector shielding materials for fast neutron analysis sys- tem. Mater Res Innovations. 19(sup5):S5-870-S5-873. doi:10.1179/1432891714Z.0000000001210.

Kankaanranta L, Seppälä T, Koivunoro H, Saarilahti K, Atula T, Collan J, Salli E, Kortesniemi M, Uusi-Simola J, Välimäki $\mathrm{P}$, et al. 2012. Boron neutron capture therapy in the treatment of locally recurred head-and-neck cancer: Final analysis of a phase I/II trial. Int J Radiat Oncol Biol Phys. 82(1):e67-e75. doi:10.1016/J.IJROBP.2 010.09.057.

Piotrowski T, Mazgaj M, Żak A, Skubalski J. 2015. Importance of atomic composition and moisture content of cement based composites in neutron radiation shielding. Procedia Eng. 108:616-623. doi:10.1016/J.PROENG.2015.06 188.

Yura Y, Fujita Y. 2013. Boron neutron capture therapy as a novel modality of radiotherapy for oral cancer: Principle and antitumor effect. Oral Sci Int. 10(1):9-14. doi: 10.1016/S1348-8643(12)00046-8. 